BULLETIN Bulletin hispanique

HISPANIQUE Université Michel de Montaigne Bordeaux

117-1 | 2015

Les poètes des rhéteurs

\title{
De la cita a la reescritura
}

El Epítome de Artiga ante la Elocuencia de Jiménez Patón y el Jardín de Hebrera y Esmir

Paolo Tanganelli

\section{(2) OpenEdition}

12 Journals

Edición electrónica

URL: https://journals.openedition.org/bulletinhispanique/3813

DOI: 10.4000/bulletinhispanique.3813

ISSN: 1775-3821

Editor

Presses universitaires de Bordeaux

Edición impresa

Fecha de publicación: 1 junio 2015

Paginación: 187-208

ISBN: 979-10-300-0174-7

ISSN: 0007-4640

Referencia electrónica

Paolo Tanganelli, «De la cita a la reescritura», Bulletin hispanique [En línea], 117-1 | 2015, Publicado el 01 junio 2018, consultado el 12 febrero 2022. URL: http://journals.openedition.org/bulletinhispanique/ 3813 ; DOI: https://doi.org/10.4000/bulletinhispanique.3813 


\title{
De la cita a la reescritura. El Epitome de Artiga ante la Elocuencia de Jiménez Patón y el Jardin de Hebrera y Esmir
}

\author{
Paolo TANganelli \\ Università di Ferrara
}

L'article examine les modalités de réécriture que Francisco José de Artiga, dans son Epitome de la elocuencia española (1692), applique aux nombreuses citations poétiques recueillies aussi bien dans l'Elocuencia española en arte de Jiménez Patón que dans le Jardín de la elocuencia de Hebrera y Esmir. L'on démontre ici qu'Artiga utilise la première version du traité de Jiménez Patón (1604) et non la version remaniée incluse dans le Mercurius trimegistus (1621).

Mots-clés: rhétorique baroque, Artiga, Jiménez Patón, Hebrera y Esmir.

Se examinan las modalidades de reescritura que Artiga, en su Epitome de la elocuencia española (1692), aplicó a numerosas citas poéticas que habían sido recopiladas tanto en la Elocuencia española en arte de Jiménez Patón como en el Jardín de la elocuencia de Hebrera y Esmir. Se demuestra que Artiga manejó sin duda la primera redacción del tratado de Jiménez Patón (1604) y no la versión retocada incluida dentro del Mercurius trimegistus (1621).

Palabras claves: retórica del Barroco, Artiga, Jiménez Patón, Hebrera y Esmir.

The article examines the methods used by Artiga, in the Epitome de la elocuencia española (1692), to re-write a conspicuous number of poetical quotations that had already been used by Jiménez Patón in his Elocuencia española en arte and by Hebrera y Esmir in Jardines de la elocuencia. It also demonstrates that Artiga certainly used the first version of Jiménez Patón's treatise (1604) and not the revised one, included in the Mercurius trimegistus (1621).

Keywords: Baroque Rhetoric, Artiga, Jiménez Patón, Hebrera y Esmir. 
E 1 Epitome de la elocuencia española (1692) es una retórica versificada en romance que prolongó su éxito hasta las primeras décadas del siglo XVIII. El título es bastante honesto, tratándose de una suerte de compendio de algunos de los manuales más importantes de la Edad de Oro. En efecto, Artiga, sin citar nunca sus fuentes, saquea y reescribe sobre todo la Elocuencia española en arte de Jiménez Patón, el Jardín de elocuencia de Hebrera y Esmir y la Censura de la elocuencia de Ormaza. Dejando de lado las relaciones entre esa última ars praedicandi y el Epitome -de las que ya me he ocupado (Tanganelli 2008 y 2011: 128-131)-, y renunciando asimismo a la pretensión de brindar un catálogo exhaustivo de los fragmentos remodelados -tarea imposible de abordar en el espacio de un artículo-, me centraré aquí en las modalidades de reescritura que el rétor oscense aplicó incluso a las citas poéticas recopiladas en los tratados de Jiménez Patón y de Hebrera ${ }^{1}$.

Por supuesto, de vez en cuando los pasajes remedados por Artiga figuraban tanto en la Elocuencia española en arte como en el Jardín de la elocuencia, visto que Hebrera había imitado a su vez el manual de Jiménez Patón. Es lo que sucede, por ejemplo, en la refundición a lo divino de un fragmento de Las lágrimas de Angélica de Barahona de Soto, donde, sin embargo, el comentario del Epitome desvela que en este caso concreto la fuente principal fue el Jardín (pero en otros lugares no resulta tan fácil determinar la derivación exacta):

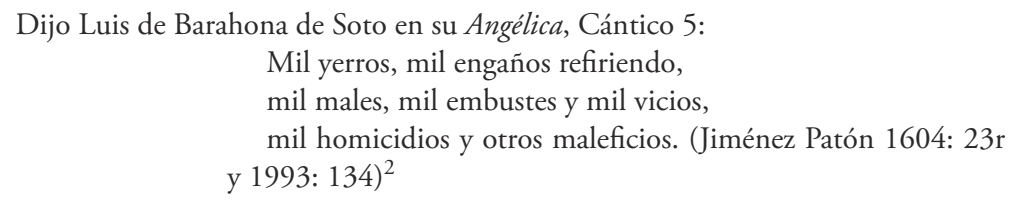

Lo cierto por lo incierto; ejemplo: «Mil almas le siguen»; afirma ser mil, aunque sean más:

Mil yerros, mil engaños refiriendo, mil males, mil embustes y mil vicios, mil homicidios y otros maleficios.

Toma el número mil, que es cierto, por lo incierto. (Hebrera y Esmir 1677: 103)

Encontrarás muchas más, si en la elocuencia las buscas; porque hallarás que lo cierto por lo incierto se pronuncia: «Vida de cien mil engaños, ¡cómo dará cuenta justa, delante del Juez Superior, el día de las angustias!»

1. Galbarro García (2010: 77) señala solo uno de estos modelos: «sigue de cerca la retórica de Hebrera y Esmir especialmente en la elocutio (sin mencionarlo)». Marco Staffa (2007-2008: VIII-XIII, XXI-XXVI), en un trabajo de grado del que fui director, ha puesto de manifiesto la recepción, en el manual de Artiga, tanto de Hebrera como de Jiménez Patón.

2. Cf. Luis Barahona de Soto (1981: 276; V, 30, vv. 6-8). 
A esta palabra «cien mil»

incierta en lugar la usa

de los muy ciertos engaños

que en una vida se juntan. (Artiga 1726: 204)

\section{La edición de la «Elocuencia» QUe Manejó ARTiga}

Antes de ocuparnos de los loci poéticos contrahechos en el Epitome, es necesario averiguar qué edición del manual de Jiménez Patón utilizó Artiga: si la princeps de 1604 o la versión retocada e incluida en el Mercurius trimegistus del ' $21^{3}$.

La Elocuencia explica la «aclamación» acudiendo a unos versos del Perseguido de Lope de Vega que, en las dos redacciones del tratado, presentan variantes de cierta envergadura. Conforme señala Pontón, la cita en la edición de 1604 no parece derivar «de ninguna de las ediciones que en la época estaban a su alcance [al de Jiménez Patón]», sino más bien de «una copia distinta de la comedia, evidentemente manuscrita y con intervenciones y errores propios de notable magnitud» (Pontón 2013: 196-197) ${ }^{4}$. Es útil cotejar el fragmento intercalado en la retórica de 1604 con el texto crítico reproducido por el mismo Pontón (vv. 2904-2911, 2936-2943):

En la comedia del Perseguido [Lope] amplificó mucho esta figura, junta con la exclamación en figura del conde que, a la mala respuesta del duque, dijo:

¿Esto señor guardado me tenías

para que fuese de la gran vitoria

el gran recebimiento y alegrías

debido, como dices, a mi gloria?

¡Ah cielo, y cómo son venturas mías,

$\mathrm{y}$ en lo mejor de mi gloriosa historia

un capítulo trágico sangriento,

me quita el gusto con igual contento!

Tras tantas esperanzas tanta pena,

tras tal seguridad tanta mudanza.

¡Oh palabras escritas en la arena,

rompida fe, traidora confianza,

uno es el alma y otro lo que suena,

ya quiebras a la misma confianza,

que yo esperaba que los mismos hombres

llaman las cosas con iguales nombres. (Jiménez Patón 1604:

$88 v-89 r$ y $1993: 214)$

3. La segunda redacción, por lo general, amplía el texto; cf. Jiménez Patón (1997).

4. Pontón (2013: 198) no cree que Jiménez Patón citara de memoria, pero admite la posibilidad que utilizara el texto de un memorilla o, incluso, papeles de actores. 
[Texto crítico con aparato $]^{5}$

¿Que esto, señor, guardado me tenías para que fuese de esta gran victoria 2905

el gran recibimiento y alegrías debido, como dices, a mi gloria?

¡Ah cielos, cómo son venturas mías!, que en lo mejor de mi dichosa historia un capítulo trágico y sangriento

me quita el gusto con igual tormento.

\author{
2904 Que esto $M$ : Esto $A B$ Pat : Eso $L$ \\ 2905 para que fuese $M L$ Pat : para despojo $A B \mid$ de esta $M:$ desta $L A B$ : \\ de la Pat \\ 2908 cielos, cómo $M L$ : cielo, cómo $A B$ : cielo, y cómo Pat | venturas $M L A$ \\ Pat : vitorias $B$ \\ 2909 que en lo mejor $M L A B:$ y en lo mejor Pat | dichosa $M L A B$ : gloriosa \\ Pat \\ 2910 trágico y sangriento $M L A B$ : trágico sangriento Pat \\ 2911 igual tormento $M$ : el gran tormento $L$ : mortal tormento $A B$ : igual \\ contento Pat
}

¿Tras tantas esperanzas, tanta pena?

¿En tal seguridad, tanta mudanza?

¡Ah palabras escritas en arena,

rompida fe, traidora confianza!

¡Una es el alma y otra lo que suena!

2940

Ya cubre al mal la misma semejanza

que suele al bien, porque los mismos hombres

todo lo llaman con iguales nombres.

\author{
2937 En tal $M L:$ Tras tal $A B$ Pat \\ 2938 Ah palabras $M L A B$ : Oh palabras Pat | en arena $M B$ : en el arena $L$ : \\ en la arena $A$ Pat \\ 2939 fe $M A B$ Pat : esa $L$ \\ 2940 Una $M L A B$ : Uno Pat | el alma $L A B$ Pat: alma $M \mid$ otra $M L$ : otro \\ es $A B$ : otro Pat \\ 2941-2943 Ya cubre... nombres $M L A B:$ Y aquiebras [sic] a la misma \\ confianza / que yo esperaba que los mismos hombres / llaman las cosas con \\ iguales nombres Pat \\ 2941 mal $M A B:$ mar $L \mid$ semejanza $M L A:$ confianza $B$ \\ 2943 iguales $M A B$ : sus mismos $L$
}

En la Elocuencia del '21 no solo se parte a la mitad esta cita y se utilizan cuatro versos para aclarar la "exclamación», sino que también se subsanan

5. Pontón (2013: 195); las siglas del aparato de Pontón son: $L=$ Lisboa 1603; $A=$ Zaragoza 1604; $B=$ Valladolid 1604; Pat= Jiménez Patón. 
algunas corruptelas: «el "y en lo mejor" del v. 2909 se corrige en "que en lo mejor", y el "contento" del v. 2911 en "tormento", enmiendas que devuelven el texto a toda la tradición conservada y que probablemente fueron cazadas al vuelo por el mismo autor o por algún oficial de imprenta con buen ojo (o buena memoria)» (Pontón 2013: 197); pero lo más relevante de la segunda redacción es la supresión de los versos finales (vv. 2938-2943 del texto crítico):

Sea la primera la exclamación [...]. Lope de Vega en la comedia de Carlos Perseguido:

$$
\begin{aligned}
& \text { ¡Ah cielo, y cómo son venturas mías } \\
& \text { que en lo mejor de mi gloriosa historia } \\
& \text { un capítulo trágico sangriento } \\
& \text { me quita el gusto con igual tormento! }
\end{aligned}
$$

Aclamación también es figura que se reduce a esta [...]. En la comedia del Perseguido amplificó mucho esta figura Lope de Vega:

¿Esto, señor, guardado me tenías para que fuese de la gran vitoria el gran recebimiento y alegrías,

Y más abajo: debido (como dices) a mi gloria?

Tras tantas esperanzas tanta pena,

tras tal seguridad tanta mudanza. (Mercurius, Jiménez Patón 1993: 412-414)

Es muy probable que este corte se deba al hecho que, precisamente en la parte conclusiva del fragmento, se concentraban las variantes más significativas entre el manuscrito citado en 1604 y el resto de la tradición del Perseguido. Sin duda el rétor más lopista del $\mathrm{XVII}^{6}$ pudo consultar sucesivamente otro testimonio de la pieza, y en 1621 ya no sabía cuál era la versión más cercana al original entre estas dos:

$$
\begin{aligned}
& \text {...ya quiebras a la misma confianza, } \\
& \text { que yo esperaba que los mismos hombres } \\
& \text { llaman las cosas con iguales nombres. } \\
& \text { Ya cubre al mal la misma semejanza } \\
& \text { que suele al bien, porque los mismos hombres } \\
& \text { todo lo llaman con iguales nombres. }
\end{aligned}
$$

De ahí -supongo- la decisión de eliminar los versos problemáticos. Pasando a la reescritura de Artiga, se puede comprobar que la retórica de 1692 recicla la cita del Perseguido solo a la hora de ejemplificar la «aclamación», mientras que no la utiliza para la «exclamación»; lo cual ya es un indicio de que el Epitome se coloca en la estela de la Elocuencia de 1604:

$$
\begin{aligned}
& \text { ¿Así, señor, me pagáis } \\
& \text { tanta pena, tanta angustia, }
\end{aligned}
$$

6. Sobre el lopismo de la Elocuencia, cf. Madroñal (2009: 96-105). 
como por vos he pasado

en vuestra adversa fortuna?

¿Estas son vuestras ofertas?

¿Estas aquellas ternuras?

¿Estas aquellas promesas

de vuestra palabra augusta? (Artiga 1726: 279)

Además -y esto es lo decisivo-, el pasaje del Epitome denuncia las falsas ofertas y vanas promesas como los versos de la comedia transcritos tan solo en la princeps de la Elocuencia, pertenecientes al fragmento suprimido en la segunda redacción: «iOh palabras escritas en la arena, / rompida fe, traidora confianza, / uno es el alma y otro lo que suena...».

La contrahechura de una cita de la Araucana confirma la pista que nos lleva a identificar el texto manejado por Artiga con la versión de principios de siglo. En el Epitome los versos de Ercilla se insertan para explicar la "perífrasis» dentro de la sección dedicada a las "Figuras que se hacen para ampliar sentencias»; la retórica de 1692, en esta parte, introduce las figuras justo en el mismo orden que sigue la Elocuencia de 1604, donde el circunloquio se ilustra en el capítulo $\mathrm{XIV}$ «De las figuras de amplificación en las sentencias»:

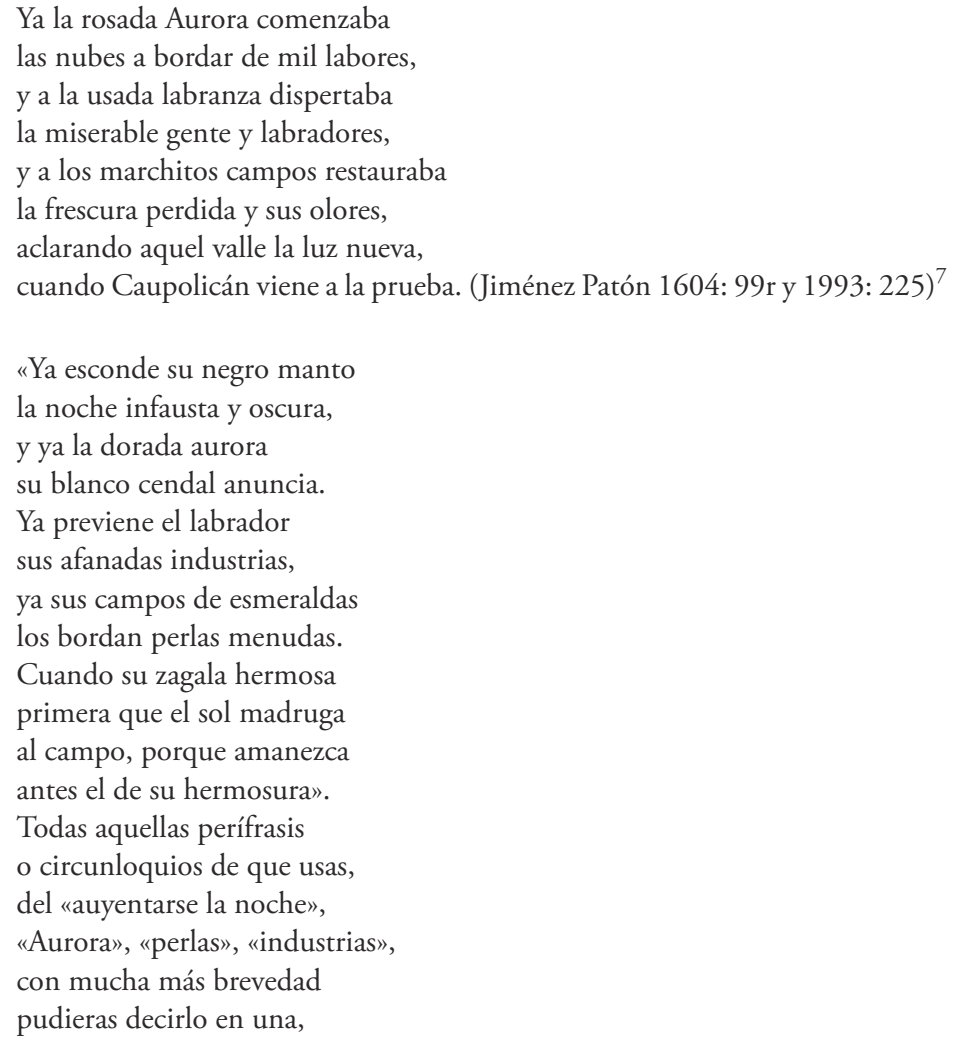

7. Obsérvese que «olores» (v. 6) es lectura errónea de «colores», cf. Ercilla (2005: 120; canto II, estrofa 50). 
diciendo: «al amanecer»,

pero no habría figura. (Artiga 1726: 287)

En cambio, en el Mercurius la "perífrasis» se declara, con ese mismo lugar de Ercilla, en el capítulo X «De las figuras que se hacen por trastueque y ornato», insertándose así dentro de una secuencia bien diferente de tropos.

No hay duda posible, entonces, acerca del uso del tratado de 1604. Por este motivo el rétor de Huesca, al enfocar uno de los modos posibles de antítesis, copia con pequeńos retoques solo los cuatro versos de un romance que aparecía en la príncipe y no la cita mucho más larga presente en la segunda impresión de la Elocuencia:

Lo segundo [modo de antítesis], cuando dos palabras contradicen a dos palabras, como en aquel romance que ponemos por ejemplo en el Apolo, del cual es esta cuarteta:

Acabáronse las burlas

y no cesaron las veras;

desminúyese el descuido

y el cuidado se me aumenta. (Jiménez Patón 1604: 61v-62r y $1993: 182)^{8}$

Lo segundo [modo de antítesis], cuando dos palabras contradicen a dos palabras, o más, como todo aquel romance que comienza:

Acabáronse las burlas,

y no cesaron las veras;

desminúyese el descuido,

y el cuidado se me aumenta;

persíguenme siempre males,

los bienes de mí se alejan.

Los más días aciagos,

y ninguna noche buena. (Mercurius, Jiménez Patón 1993: 364-365)

La segunda [manera de antítesis], que se forma

en cuatro voces opuestas,

han de formar dos a dos

elegante competencia.

$[\ldots]$

«Ya se acabaron las burlas,

ya principiaron las veras,

disminúyese el descuido

y el cuidado se me aumenta». (Artiga 1726: 232)

8. No disponemos de ninguna información acerca de este Apolo; obra que habría escrito el mismo Jiménez Patón y que no se vuelve a mencionar en la edición de 1621; cf. Madroñal (1993: 88). 


\section{No SOLO VUELTAS A LO DIVINO}

Artiga, como sugiere el título completo de su retórica, comparte con Hebrera la voluntad de dirigirse a un público variado que incluyese, sin privilegiarlos, a los predicadores; de hecho, en este manual el orador sagrado ya no tiene al lado solo al literato o al político, sino a cualquier sujeto que desee expresarse con agudeza en las conversaciones mundanas o en las epístolas. Sin embargo, al margen de semejante dilatación laica del horizonte, no son pocos los ejemplos de talante religioso en el Epitome. Por ejemplo, Artiga imita el fragmento del «Romance a la Pasión» de Paravicino con el que Hebrera explica la sujeción:

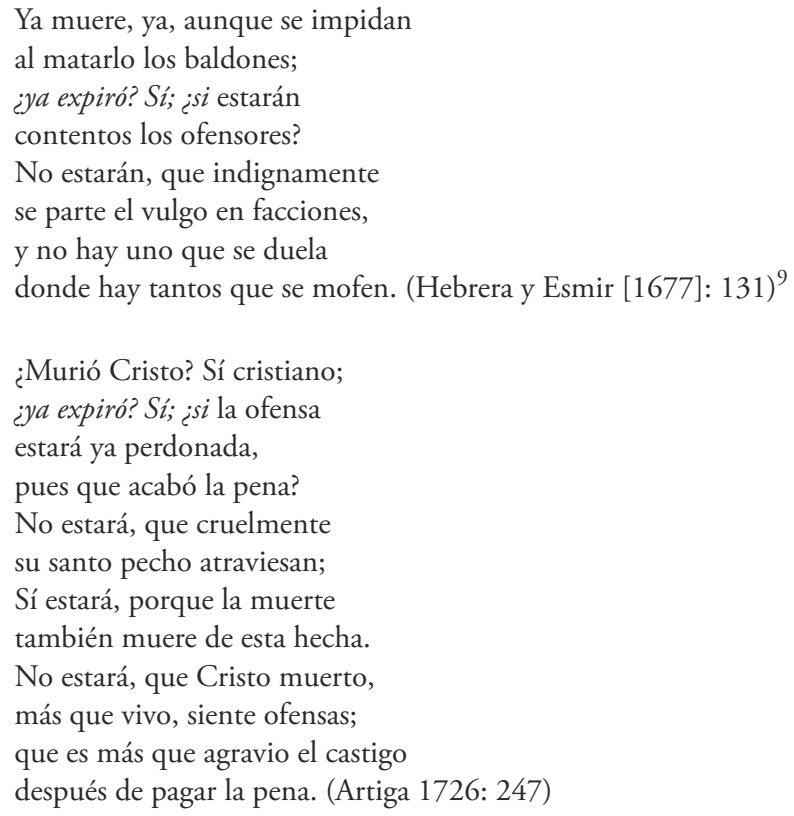

Y, además, vierte a lo divino un par de cuartetos de endecasílabos; amplifica uno citado en la Elocuencia y procedente de una comedia que no he logrado identificar:

Interrogación, en griego erotima, es cuando no solo por preguntar, sino juntamente por hacer instancia preguntamos, como en la comedia del Caballero Penitente dice:

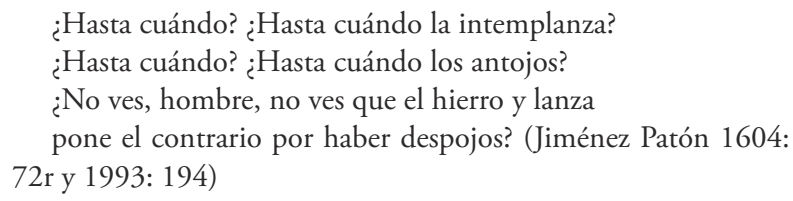

9. En realidad, el texto de Paravicino (1645: 6) puntuaba «iya escribió!, sí». La edición moderna (Paravicino, 2002: 135; vv. 145-152) transcribe erróneamente «lo mofen» en lugar de «se mofen». 
La interrogación o erotima,

fingiéndote lo que dudas,

has de hacerla para hacer

más extraña la pregunta.

"¿Hasta cuándo, mi Jesús,

han de durar las angustias?

¿Hasta cuándo han de durar

de este mar las amarguras?

¿Hasta qué tiempo o qué día

queréis, Señor, no se cumpla

el destierro de la gracia

y la prisión de la culpa?

¿Hasta cuándo heis de tenerme

preso en esta carne inmunda?

¿Cuándo saldré de esta cárcel

y entraré en la sepultura?

¿Cuándo, Señor, he de veros?

¿Cuándo he de gozar la suma

gloria infinita que aguardan

tanta pena y tanta angustia?» (Artiga 1726: 258-259)

Y remeda otro, del soneto «A la muerte de don Anastasio Pantaleón de Ribera» de Juan de Vidarte, que había leído en el Jardín de Hebrera (obsérvese, sin embargo, que los versos de Vidarte ya trazaban un paralelo in absentia entre la defunción del amigo poeta, autor de la Fábula de Europa, y la expiración de Cristo):

\section{Obscura noche baña al claro día y a la confusa noche un caos terreno. \\ Todo lo escucho de gemidos lleno cuanto alberga en sí el orbe, cuanto cría.}

Toma a la noche y al día por tinieblas y luces de que son causas. (Hebrera y Esmir [1677]: 104) ${ }^{10}$

«El día que Cristo muere

se vistió de noche oscura,

que es justo nazca la gracia

anocheciendo a la culpa».

$\mathrm{El}$ «vestirse obscura noche»

es donde está la figura,

porque en lugar de «tinieblas»

puse por ser causa suya. (Artiga 1726: 205)

También en otros casos la reescritura transforma a fondo el fragmento original, aunque ya no se trate de vueltas a lo divino. Así, de la representación de una mujer se puede pasar a la de un hombre:

10. El soneto fúnebre de Juan de Vidarte figura en las Obras de Pantaleón de Ribera (1648: 154v [pero 156v]). 
Concesión o sincoris es cuando lo que concedemos y confesamos ser así, antes es en nuestro favor que nos daña, como en aquel romance:

Confieso que eres hermosa,

bizarra y de lindo talle;

y que con donaire y brío

bailas, danzas, cantas, tañes;

y que has muerto más cristianos

que tienes gotas de sangre,

no con espada ni lanza,

sino con armas más graves, etc. (Jiménez Patón 1604: 73v y 1993: 195$)^{11}$

La concesión o sincoris

haces, concediendo muchas

circunstancias, más a todas

las contradices en una.

«Confieso que don Fulano

es muy bizarro y son muchas

las gracias, prendas, donaires

con que su persona ilustra:

que canta con gran primor,

que tañe con gran dulzura,

que pica bien un caballo,

que pelea con gran furia.

Que es muy entendido y sabio,

mas ¡qué importa! Si lo ofusca

y lo desvanece todo

su lengua, cuando murmura». (Artiga 1726: 262-263)

\section{Y la descripción metafórica de un caballo, tópicamente parangonado con un ave, puede trasladarse a la de un ciervo:}

De unos animales de una especie a otros de la misma; ejemplo: «vuela el caballo", "pace la abeja».

$$
\begin{aligned}
& \text { Volaba el ligero bruto } \\
& \text { tanto que los que miraban } \\
& \text { águila lo distinguían, } \\
& \text { en piélagos de esmeralda. } \\
& \text { Las verdes rizadas plumas, } \\
& \text { como al aire se ondeaban, } \\
& \text { no fingidas parecieron, } \\
& \text { sino naturales alas. }
\end{aligned}
$$

Trasládanse del ave las propiedades al caballo. (Hebrera y Esmir [1677]: 97) ${ }^{12}$

Es la tercera, la que

de brutos a brutos se usa,

y pasando unos en otros

11. Estos versos recuerdan el romance lopiano Mira, Zaide, que te aviso...: «Confieso que eres valiente, / que hiendes, rajas y partes, / y que has muerto más cristianos, / que tienes gotas de sangre», Vega (1998: 12).

12. Tal vez se trate de un ejemplo inventado por el mismo rétor. 
sus propiedades permutan:

«Volaba el ciervo trepando

intrincadas espesuras,

al aire de sus alientos

y a las alas de sus puntas».

El volar es propio al ave

y para el ciervo se usurpa

para ponderar mejor

su gran ligereza y furia. (Artiga 1726: 196-197)

\title{
3. VERSOS CONSERVADOS Y RETOCADOS
}

A menudo los nexos intertextuales son tan tenues que apenas se reducen a una o dos palabras:

\author{
En el espejo los ojos \\ y en los cabellos el peine, \\ en su vida el desengaño, \\ los deseos en la muerte.
}

Donde para hacer sentido en cada uno de estos versos se ha de entender esta palabra: «teniendo». (Jiménez Patón 1604: 53v y 1993: 171; la cursiva es mía) ${ }^{13}$

«Los ojos en sus delitos,

la mano en su calavera,

el deseo en su escarmiento

y el propósito en su enmienda».

En todas las cuatro líneas,

aunque no se manifiesta,

se oculta este verbo «tiene»

por esta figura mesma. (Artiga 1726: 223; la cursive es mía) $)^{14}$

Pero en ocasiones, además de estas débiles huellas léxicas, Artiga mantiene la estructura del modelo por lo que concierne a la $\sin \operatorname{taxis}^{15} \mathrm{y}$ a su andamiaje retórico. Si en un caso conserva una secuencia de anadiplosis,

13. En el Romancero general (González Palencia, 1947: I, 26; libro I, núm. 25) la variante «sus deseos» en lugar de «los deseos».

14. Muy parecida es esta otra reescritura: «Ya conozco tus caricias: / tú engańas y no enamoras, / que el decirme que me quieres / se ha de entender por la bolsa. // Se entiende bolsa por el dinero que se contiene en ella», Hebrera y Esmir ([1677]: 104-105); versos atribuidos a Quevedo. "'Mozo novel, esa dama / no se inclina a tu hermosura, / ni al carińo que le muestras, / sino al bolsillo que ocultas". / Del bolsillo por dinero / con gran propiedad abusa, / porque le contiene en sí, / en quien la elocuencia funda», Artiga (1726: 206).

15. Puede conservar, por ejemplo, la correlación desde ... hasta: «...y así se entiende cuando decimos que la muerte no perdona dende el ceptro al abarca, que es decir que mata a monarcas poderosos, príncipes y reyes, y los humildes gañanes que son los que calzan abarcas; el brocado y el sayal se dice por los estados de ricos y pobres, y así dijo una sátira contra el amor: // Insolente mal criado / perseguidor general / desde el que viste sayal / hasta el que pisa brocado", Jiménez Patón (1604: 27v) y Jiménez Patón (1993: 141); cf. González Palencia (1947: I, 422; libro VIII, núm. 645). "Desde el más tosco sayal / hasta la púrpura augusta, / por distintas sendas todos / vamos a la sepultura." / Toma al sayal por el pobre / y a la púrpura la usa / en lugar del rey, formando / una frase muy aguda», Artiga (1726: 207). 
Del ver procede el mirar,

del mirar el advertir,

del advertir el oír,

y del oír el hablar. (Hebrera y Esmir [1677]: 119) ${ }^{16}$

Del mirar sale el deseo,

del deseo la insolencia,

de la insolencia el pecado,

del pecado, pena eterna. (Artiga 1726: 219)

en otro reemplaza el poliptoton del verbo amar, que caracteriza el íncipit de un soneto atribuido a Lope de Vega, por el del sinónimo querer:

Lo tercero [modo de antítesis], cuando la sentencia se opone y contradice a la sentencia, como es aquel soneto de Lope de Vega, donde la sentencia del un verso contradice la del otro:

Amé, Filis, amé, mientras amaste;

rompí la fe, cuando la rompiste.

Mientras tú fuiste brasa, arder me viste;

helado agora estoy, pues tú te helaste. (Jiménez Patón 1604: 62r y 1993: 182; la cursiva es mía) ${ }^{17}$

La tercera es más vistosa

y elegante, porque enseña

con dos sentencias a hacer

una elocuente pelea:

"Quise cuando tú quisiste,

te ausentaste y tuve ausencia,

me olvidaste y te olvidé,

yo contento y tú contenta.»

En el «quisiste» y el «quise»,

en «ausente» $\mathrm{y}$ en «ausencia»,

en «olvidé» y «olvidaste»,

esta antítesis pelea. (Artiga 1726: 233; la cursiva es mía)

Como regla general, se podría afirmar que, al menos en sus imitaciones más respetuosas del dictado original, el rétor oscense suele empezar por copiar, con pequeños retoques o permutaciones, el verso o el dístico inicial de la cita, para luego irse alejando cada vez más del modelo conforme procede con la reescritura. Como es obvio, en la adaptación, que siempre pretende ocultar la fuente, influyen tanto razones métricas (por el paso de endecasílabos a octasílabos) como de rima (verbigracia cuando las redondillas se tienen que

16. Hebrera y Esmir cita un fragmento del auto del Polifemo de Juan Pérez de Montalbán incluido dentro del Para todos (1633); cf. Pérez de Montalbán (1661: 330).

17. El rétor solo trascribe el cuarteto inicial. Francisco J. Martín (Jiménez Patón 1993: 182, nota 275) no ofrece ningún dato acerca de estos versos, ignorando que Sánchez Mariana (1989) había descubierto que este soneto atribuido a Lope figura, copiado a mano, en el ejemplar de La hermosura de Angélica (Madrid, en la emprenta de Pedro Madrigal, 1602) conservado en la Biblioteca Nacional de España (sign. R/5403). 


\section{amoldar a la cadencia del romance). Por ejemplo, mantiene inalterado el primer octasílabo en estos casos:}

... solo trairé una copla imperfecta celebrada por su artificio poético; llegando a un marqués a que firmase que mataría su rey, escribió:

$$
\begin{aligned}
& \text { Matar al rey no es mal hecho, } \\
& \text { antes ser cuchillo afirmo } \\
& \text { del que lo mataré; y firmo. } \\
& \text { El Marqués }
\end{aligned}
$$

Con la cual copla cumplió con los conjurados o traidores, y después se disculpó con el rey, porque de dos manera leída hace dos sentidos. Uno: «No es mal hecho matar al rey, antes seré de él cuchillo y lo mataré». Otro leyendo así: «Matar al rey, eso no, que es mal hecho, antes seré cuchillo del que lo matare». (Jiménez Patón 1604: 100r-100v y 1993: 226; la cursiva es mía)

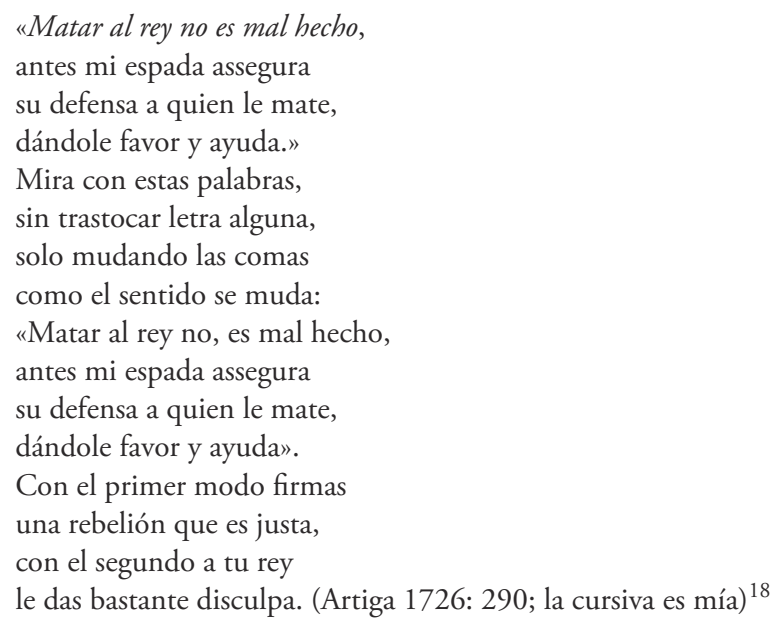

Lo quinto es un modo contrario a este que se dice paradiástole y es cuando dos cosas muy semejantes se van apartando, como en esta redondilla:

Es fuego amor y no alumbra,

adquiere almas y no vida,

quítala y no es homicida,

es celestial y no encumbra. (Jiménez Patón 1604: 63r y 1993:

184; la cursiva es mía)

La quinta se hace sacando

de las cosas cosa opuesta

por efecto, y $1[\mathrm{a}] \mathrm{s}$ ajunta

con contraria diferencia:

"Fuego es amor y no alumbra,

es un lince y obra a ciegas,

18. También en este caso Artiga sigue el orden de las figuras de amplificación que caracteriza a la Elocuencia de 1604. En la reescritura de 1621 Jiménez Patón (1993: 372) explica la anfibología en la sección de las figuras «que se hacen por trastueque y ornato». 
es un deleite que aflige,

y es un gusto que atormenta».

Esta agudeza se forma

en efectos que discuerdan,

de que no dé lumbre el fuego

y que el deleite dé pena. (Artiga 1726: 235; la cursiva es mía)

La casuística es relativamente amplia. Artiga puede asimismo conservar grosso modo los primeros versos de una redondilla, como se aprecia en este otro ejemplo donde, después de retocar el dístico de apertura, fabricando una pareja sinonímica («abrasa y quema») que le permite eliminar "el pecho», remodela los dos versos siguientes para rescatar la estereotipada antítesis fuego (pasión) / agua (lágrimas):

La corrección es cuando la palabra se corrige y enmienda con otra, por parecer que aquella no explica lo que se quiere bastantemente. Hácese en dos maneras, porque, si se corrige antes que se diga, se llama prodiortosis. Así dijo Lope de Vega en la Arcadia:

Esto que me abrasa el pecho

no es posible que es amor,

sino un rabioso furor

del mal que el amor me ha hecho. (Jiménez Patón 1604:

65r-65v y 1993: 187; la cursiva es mía) ${ }^{19}$

Corrección es muy gallarda

figura, y se usa de ella

corrigiendo una palabra

con otra que mejor suena.

Sus variedades son muchas

por sus muchas diferencias:

$[\ldots]$

La segunda, la palabra

que en su entendimiento lleva, aun antes de pronunciarla,

la corrige con sentencia.

[...]

"No es posible que sea fuego

esto que me abrasa y quema,

porque con agua se aviva,

pues mis lágrimas se aumentan». (Artiga 1726: 240-241; la cursiva es mía)

En el remedo de otra redondilla mantiene, además del verso inicial, la arquitectura completa de la copla, censurando las referencias a la onomástica morisca que delatarían la fuente y realizando un par de sustituciones necesarias para respetar la asonancia $u$ - $a$ (cambia "esperanza» con «hermosura» $\mathrm{y}$ "podré ver a Zaida» con «mi Celia se oculta»).

19. Desde luego, «rabioso furor», en lugar de "celoso furor», es variante de la Elocuencia de Jiménez Patón en sus dos redacciones; cf. el texto del Mercurius (Jiménez Patón, 1993: 369) y Vega (2012: 420; libro III, segundo poema de Olimpio, estrofa 1, vv. 1-4). 
Optación es una significación del deseo, como dice aquel romance:

Asi no marchite el tiempo

el abril de tu esperanza,

que me digas, Tarfe amigo,

dónde podré ver a Zayda. (Jiménez Patón 1604: 68v-69r y 1993: 190-191; la cursiva es mía) ${ }^{20}$

La primera es optación,

y es elegancia que se usa

para explicar un deseo,

que agradecimiento anuncia.

[...]

"Asi no marchite el tiempo

ese abril de tu hermosura,

que me digas Clori bella,

dónde mi Celia se oculta.» (Artiga 1726: 252; la cursiva es mía)

En esta misma categoría se podría insertar también la reelaboración de un pasaje de La hermosura de Angélica. De este excerptum Artiga utiliza el sintagma inicial del primer verso («Tres cosas») y el segundo verso -suprimiendo los artículos para reducir el endecasílabo primigenio («la mujer, la privanza y la fortuna») a la medida de un octasílabo («mujer, privanza y fortuna»)-; pero desplaza dichas palabras en el cierre del rifacimento, cuya amplificación aprovecha una secuencia anafórica de exclamaciones que modifica el sentido de los versos lopescos (en el texto del Fénix solo la fortuna es ontológicamente mudable, mientras que en la reescritura del rétor no se manifiesta ninguna diferencia entre los elementos del tópico terno de la inconstancia):

Tres cosas tiene[n] la mudanza en una:

la mujer, la privanza y la Fortuna.

Justa privanza nunca vino al suelo,

leal amor jamás faltó a su cargo,

Fortuna sí, que al varïar del cielo

está sujeta a plazo corto o largo. (Jiménez Patón 1604: 95v y 1993: 221; la cursiva es mía) $)^{21}$

"¿Qué presto de amor se cansa

la mujer que más lo jura!

¡Qué presto se desvanece

la privanza más segura!

¡Qué presto el círculo acaba

de su rueda la fortuna!

¡Qué presto encumbra al que postra!

¡Qué presto postra al que encumbra!

20. En el Romancero general (González Palencia, 1947: I, 80; libro III, núm. 109) «marchita» en lugar de «marchite».

21. El Fénix había escrito «en plazo» al v. 468 en lugar del erróneo «a plazo» de la Elocuencia; cf. Vega (2005: 619-620; canto XVII, estrofa 58, vv. 7-8 y estrofa 59, vv. 1-4). 
Sabe Fabio que en el mundo

estas tres cosas no duran

ni permanecen, que son

mujer, privanza y fortuna». (Artiga 1726: 283; la cursiva es mía)

Es mucho más raro que Artiga recupere elementos léxicos de versos sucesivos a los dos primeros de la cita. Puede actuar así cuando la reproposición de los metros iniciales delataría la fuente imitada, como sucede con un fragmento del famoso romance Oid, señor don Gaiferos... ${ }^{22}$ que Hebrera ya le había copiado a Jiménez Patón:

Énfasis o significación es cuando se da más a entender con las palabras y modo de decir que algo se dice, que no es lo que se dice [...] me parece bonísima la de Miguel Sánchez, en el romance que dice:

Melisendra está en Sansueña, vos en París descuidado; vos ausente, ella mujer,

harto os he dicho: miraldo. (Jiménez Patón 1604: 80v-81r y 1993: 204; la cursiva es mía) ${ }^{23}$

Énfasis es cuando el modo de hablar dice más que las palabras: [...]

Melisendra está en Sansueña,

vos en París descuidado;

vos ausente, ella mujer,

harto os he dicho: miraldo. (Hebrera y Esmir [1677]: 142; la cursiva es mía)

La énfasis se hace cuando

de tales palabras se usa

que más dice en las que calla,

que en aquellas que pronuncia.

$[\ldots]$

"Ya te he dicho que, si a fiestas

envías tu mujer, no hay duda

que tú ausente y ella hermosa,

harto te he enseñado, estudia». (Artiga 1726: 271-272; la cursiva es mía)

O simplemente cuando los versos finales resultan fundamentales para ilustrar la figura comentada; como en esta cita del romance Aqui entre la verde juncia... de Góngora, aducida para explicar la «semejanza», en la cual la sentencia conclusiva, casi un epifonema, brinda las claves de la ingeniosa comparación:

22. También en el Quijote se evocan estos versos; cf. Alonso Asenjo (2000: 43). Este es el párrafo cervantino: «Y aquel personaje que allí asoma con corona en la cabeza y ceptro en las manos es el emperador Carlomagno, padre putativo de la tal Melisendra, el cual, mohíno de ver el ocio y descuido de su yerno, le sale a reñir; y adviertan con la vehemencia y ahínco que le rińe, que no parece sino que le quiere dar con el ceptro media docena de coscorrones, y aun hay autores que dicen que se los dio, y muy bien dados; y después de haberle dicho muchas cosas acerca del peligro que corría su honra en no procurar la libertad de su esposa, dicen que le dijo: "Harto os he dicho: miradlo"”, Cervantes (2004: I, 925; II parte, cap. 26).

23. Cf. González Palencia (1947: I, 78; libro III, núm. 104). 
Que los dos nos parecemos

al roble que más resiste

los soplos del viento airado:

tú en ser dura, yo en ser firme. (Hebrera y Esmir [1677]: 22; la cursiva es mía) ${ }^{24}$

«Yo a amarte, tú a resistirte,

errados vamos sin duda;

al hierro nos parecemos:

yo en ser firme, tú en ser dura.

Si mi voluntad es yerro

y también es yerro la tuya:

los yerros de los amantes

el fuego de amor los junta». (Artiga 1726: 294; la cursiva es mía)

\section{AMplificaCión Y «DETraCtio»}

Aunque Artiga de vez en cuando opte por la supresión de versos, en sus rifacimenti prima a todas luces la estrategia amplificativa; pero su exornación nunca logra compensar, o al menos atenuar, el proceso de sustancial vaciamiento y trivialización de los modelos que caracteriza la galería de contrahechuras del Epitome:

Aquí también se ha de reducir la imprecación o maldición, que es cuando a alguno le deseamos mal y lo pedimos con ahínco, como en el romance que comienza: «Pues que te vas Reduán». Dice:

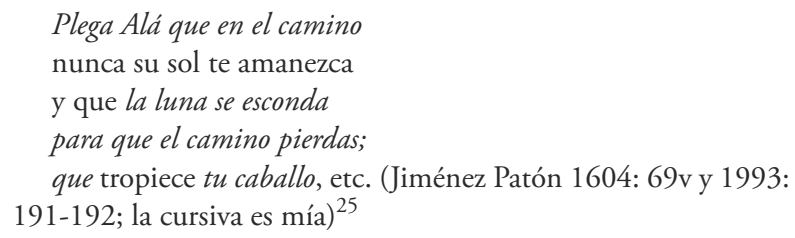

La imprecación con enojo

maldiciones articula,

por rancor o por pedir

venganza contra una injuria.

$[\ldots]$

«Plegue a Dios que en el camino

encuentres la desventura,

que tu caballo te arrastre

y en nadie encuentres ayuda.

O que en el más mal camino

se te obscurezca la luna,

porque te pierdas y encuentres

alguna traición oculta.

Y que perdido y culpado

24. Cf. Góngora y Argote (1998, I, 286; vv. 29-32).

25. En el Romancero general (González Palencia, 1947: I, 89; libro III, núm. 123) «Plegue a Alá» en lugar de «Plega Alá». 
halles en las espesuras alguna fiera, que vengue

el honor de mi hermosura». (Artiga 1726: 253-254; la cursiva es mía)

En este remedo, después del traslado del verso inicial con la acostumbrada extirpación del barniz morisco («Dios» que desplaza a "Alá»), el epitomador reelabora los versos siguientes sin respetar un orden exacto: el tercero y el cuarto del fragmento citado en la Elocuencia («y que la luna se esconda / para que el camino pierdas») confluyen en el sexto y en el hemistiquio inicial del séptimo de la nueva composición («se te obscurezca la luna / porque te pierdas...»); el quinto del original ("Qué tropiece tu caballo») inspira el tercero de la imitación ("qué tu caballo te arrastre»). Y la amplificación deriva tanto de la dilatación del augurio de muerte del segundo verso («nunca su sol te amanezca») -que se transforma en la gradatio "encuentres la desventura», «y encuentres / alguna traición oculta», "halles en las espesuras / alguna fiera»-, como de la decisión de explicitar el tema del lamento femenino por el honor traicionado (elemento implícito en el modelo, ya que los lectores de Jiménez Patón debían conocer de sobra el famoso romance Pues que te vas Reduán...).

Cuando se trata de reducir endecasílabos a octasílabos, suelen alternarse amplificatio y detractio, como es posible observar en la reescritura de un soneto de Lupercio Leonardo de Argensola:

En cosas amorosas hay muchos sonetos hechos en esta figura, de los cuales sea ejemplo uno de Lupercio Leonardo:

No temo los peligros del mar fiero

ni de un scita la odiosa servidumbre,

pues alivia los hierros la costumbre

y el remo grave puede hacer ligero;

ni oponer este pecho por terrero

de flechas a la inmensa muchedumbre,

ni envuelta en humo la dudosa lumbre

ver ni esperar el plomo venidero.

Mal que tiene la muerte por extremo

no lo debe temer un desdichado,

mas antes escogerlo por partido.

La sombra sola del olvido temo,

pues es como no ser uno olvidado

y no hay mal que se iguale al no haber sido. (Jiménez Patón 1604: 90r-90v y 1993: 215$)^{26}$

26. Dicho soneto apareció en 1605 tanto en las Flores de Espinosa (1605: 132r-132v) como en la Segunda parte del Romancero general (Madrigal 1605: 186v). Señalo las variantes del texto que ofrece Jiménez Patón (Pat) con respecto a la edición de J. M. Blecua (Leonardo de Argensola 1972: 49-50) y la que recogen Espinosa (Flores) y la Segunda parte del Romancero general (SP): 2 odiosa Pat Flores Blecua : dura SP // 4 el remo Pat Flores: al remo SP Blecua // 5 pecho Pat Flores Blecua: trecho SP // $\mathbf{6}$ la inmensa Pat Flores Blecua: una inmensa SP // 7 ni envuelta Pat Blecua : o envuelta Flores SP | lumbre Pat Flores Blecua : cumbre SP // 8 ni esperar Pat: y esperar Flores SP Blecua // 11 escogerlo Pat: procurarle Flores SP: escogerle Blecua // 12 sola del olvido temo Pat Blecua : del olvido es la que temo Flores SP // 13 pues Pat: porque Flores SP 
«No temo del mar soberbio

las infaustas desventuras

que en desgraciadas tormentas

la humana ambición sepultan.

No temo el verme oprimido

entre la otomana chusma,

ni la esclavitud que el moro

viva muerte en remo anuncia.

$\mathrm{Ni}$ la lluvia de saetas

que a mi corazón se apuntan,

no las balas que dudosas

humo muestran, muerte ocultan.

$\mathrm{Ni}$ todas cuantas desdichas,

trabajos, penas y angustias,

si todas se han acabar.

No temo mal que no dura». (Artiga 1726: 280)

La imitación potencia el esqueleto anafórico (las repeticiones de "No temo" y de «ni»), desarrollando sobre todo algunas imágenes del primer cuarteto: «los peligros del mar fiero" se pintan en el Epitome como «del mar soberbio / las infaustas desventuras / que en desgraciadas tormentas / la humana ambición sepultan», así como el verso "de un scita la odiosa servidumbre» experimenta un proceso de duplicación bimembre: «el verme oprimido / entre la otomana chusma, / ni la esclavitud que el Moro». Después de la amplificación inicial, se mantiene cierto equilibrio entre los dos textos: la descripción de la muerte con flechas y con armas de fuego, que domina el segundo cuarteto del soneto, ocupa cuatro versos también en el remedo. En cambio, sufren una notable detractio los tercetos, ya que Artiga solo conserva la idea piadosa que no se debe temer ningún mal terreno "que tiene la muerte por extremo», ignorando la conclusión casi silogística de la composición de Lupercio Leonardo: el mal mayor es el olvido, porque ser olvidado es como no haber sido nunca.

Un procedimiento análogo se detecta en la remodelación de otro fragmento de la Hermosura de Angélica que Jiménez Patón había intercalado para ilustrar la evidentia:

Como lo dice Lope de Vega pintando un monstruo en la Angélica, diciendo:

Era su forma humana y de un velloso

cuero cubierta, por extremo ardientes

los vivos ojos, que un vellón cerdoso

mostraba apenas por las negras frentes,

ceñidas de un espino verde hojoso,

cuyas puntas agudas y pungentes,

trabadas en las cerdas intricadas,

eran sus eslabones y lazadas.

Las plantas, vueltas hacia atrás, ligeras,

como se ven los feos abarimos,

con que pueden trepar palmas enteras

Blecua | uno olvidado Pat: un olvidado Flores SP Blecua // $\mathbf{1 4}$ al no Pat Flores Blecua : a no SP. 
y gozar de sus dátiles opimos; cubría de yedra las cinturas fieras

trabadas ramas, hojas y racimos,

que el deshonesto entre ellos es pecado

más que homicida y hurto castigado. (Jiménez Patón 1604: 80r-80v y 1993: 203) $)^{27}$

«Era su forma, aunque humana,
una cerdosa figura,
tanto que sus blancos ojos
entre sus sienes se ocultan.
Su amarilla frente ciñe
una guirnalda de murtas,
cuyas hojas, siempre infaustas,
funestas carnes ocultan.
Así como al roble seco
la verde yedra, que ofusca
con lo verde de sus hojas
la corteza más adusta.
Tal era el monstruo que vi
salir de entre las incultas
matas, rematando y rompiendo
intrincadas espesuras». (Artiga 1726: 271)

En comparación con el modelo lopiano, la reescritura de Artiga resulta bastante más pobre en la vertiente de los adjuntos, aunque al principio del retrato intente guardar la mayoría de las correspondencias: «de un velloso / cuero cubierta» > «cerdosa figura»; «los vivos ojos, que un vellón cerdoso / mostraba apenas» > «sus blancos ojos / entre sus sienes se ocultan»; «las negras frentes, / ceñidas de un espino verde hojoso» > «Su amarilla frente ciñe / una guirnalda de murtas»; «cuyas puntas agudas y pungentes» > «cuyas hojas, siempre infaustas». Y de nuevo la detractio se aprecia en la parte conclusiva, ya que el remedo de Artiga omite la descripción de las «plantas» del monstruo y de sus habilidades a la hora de trepar sobre las palmas. Además, el detalle de la yedra que cubre sus pudenda se reduce a la simple metáfora de la yedra enroscada en el roble.

Aunque no me haya detenido en todos los ejercicios de reescritura llevados a cabo en la postrera retórica del Siglo de Oro, creo que, de cualquier forma, habrá quedado patente el valor simbólico de la operación de remodelación ensayada por Artiga. No se trata, en efecto, tanto de escudrińar la degradación de unas auctoritates o de horrorizarse ante una serie de plagios mal realizados, cuanto, por el contrario, de comprender el alcance histórico de esa quiebra que sufre el mecanismo de la cita. La retórica aurisecular se había alimentado de su ósmosis con las poéticas coevas, ya que los versos citados en los manuales, lejos de

27. Señalo las pequeñas variantes de la cita de Jiménez Patón con respecto a la edición de la Hermosura al cuidado de Trambaioli (Vega, 2005: 375-376; canto VII, estrofas 40 y 41): «por extremo» en lugar de "y por extremo» (v. 314), «hacia atrás» en lugar de «hacia tras» (v. 321), «cubría» en lugar de «cubren» (v. 325) y «homicida» en lugar de «homicidio» (v. 328). 
reducirse a simples adornos, reflejaban y transmitían al menos implícitamente las diferentes concepciones estéticas de los mismos rétores. Por esta razón, la desaparición o el sistemático camuflaje de las citas en el Epitome debe leerse como el síntoma más claro del definitivo estancamiento de la retórica en España.

\section{Bibliografía}

Alonso Asenjo, Julio «Quijote y romances: uso y funciones», en R. Beltrán (ed.), Historia, reescritura y pervivencia del Romancero. Estudios en memoria de Amelia García-Valdecasas, Valencia, Universitat de Valencia, 2000, pp. 25-65.

Argensola, Lupercio Leonardo de, Rimas, ed. de J. M. Blecua, Madrid, Espasa-Calpe, 1972.

Artiga, Francisco José, Epitome de la elocuencia española, arte de discurrir y hablar con agudeza y elegancia, en todo género de asumptos, de orar, predicar, argüir, conversar, componer embajadas, cartas y recados; con chistes que previenen las faltas, y ejemplos que muestran los aciertos, Pamplona, por Alonso Burguete, 1726.

Barahona de Soto, Luis, Las lágrimas de Angélica, ed. de José Lara Garrido, Madrid, Cátedra, 1981.

Cervantes, Miguel de, Don Quijote de la Mancha, Galaxia Gutemberg - Círculo de Lectores - Centro para la edición de los clásicos españoles, s. 1., 2004, 2 vols.

Ercilla, Alonso de, La Auracana, ed. de Isaías Lerner, Madrid, Cátedra, 2005.

Espinosa, Pedro, Primera parte de las flores de poetas ilustres de España..., Valladolid, Por Luis Sánchez, 1605.

Galbarro García, Jaime, «Hacia una catalogación de las retóricas españolas más importantes del siglo XVII. Modelos, tendencias y canon poético», en B. López Bueno (ed.), El canon poético en el siglo XVII, Sevilla, Universidad de Sevilla, 2010, pp. 73-92.

Góngora y Argote, Luis de, Romances, ed. de Antonio Carreira, Barcelona, Quaderns Crema, 1998, 4 vols.

González Palencia, Ángel (ed.), Romancero general (1600, 1604, 1605), CSIC, Madrid, 1947,2 vols.

Hebrera y Esmir, José Antonio de, Jardin de la elocuencia. Flores que ofrece la retórica a los oradores, poetas y politicos, Zaragoza, por los Herederos de Diego Dormer, [1677].

Jiménez Patón, Bartolomé, Elocuencia española en arte..., Toledo, por Thomas de Guzman, 1604.

Jiménez Patón, Bartolomé, Elocuencia española en arte, ed. de Francisco J. Martín, Barcelona, Puvill, 1993.

Jiménez Patón, Bartolomé, Elocuencia española en arte. Edizioni del 1604 e del 1621: stampa sinottica delle varianti, ed. de Gianna Carla Marras, Pisa, Giardini, 1997.

Madrigal, Miguel de, Segunda parte del Romancero general, Valladolid, Por Luis Sánchez, 1605.

Madroñal, Abraham, «Aportaciones al estudio del maestro Jiménez Patón (dos obras inéditas y casi desconocidas)», Criticón, 69 (1993), pp. 83-97. 
Madroñal, Abraham, Humanismo y filología en el Siglo de Oro. En torno a la obra de Bartolomé Jiménez Patón, Universidad de Navarra / Iberoamericana / Vervuert, Madrid / Frankfurt am Main, 2009.

Pantaleón de Ribera, Anastasio, Obras de Anastasio Pantaleón de Ribera, s. 1., por Diego Díaz de la Carrera, 1648.

Paravicino, Hortensio Félix, Obras posthumas divinas y hvmanas de don Hortensio Felix Paravicino y Arteaga, Lisboa, Por Paulo Craeesbeck, 1645.

Paravicino, Hortensio Félix, [Poesías completas] Obras póstumas, divinas y humanas de don Félix de Arteaga, ed. de Francisco Javier Sedeño Rodríguez y J. Miguel Serrano de la Torre, Málaga, Universidad de Málaga, 2002.

Pérez de Montalbán, Juan, Para todos... Alcalá, por María Fernández, 1661.

Pontón, Gonzalo, "Fortuna de unos versos de El perseguido», Anuario Lope de Vega. Texto, literatura, cultura, XIX, 2013, pp. 189-203.

Sánchez Mariana, Manuel, «Un manuscrito fragmentario de la Dragontea, y un soneto poco conocido de Lope», Manuscrt.cao, II, 1989, pp. 21-23.

Staffa, Marco, "Epitome de la elocuencia española» di Francisco José Artiga. Edizione e studio, Ferrara, Università di Ferrara, 2007-2008.

Tanganelli, Paolo, «La crisis de la oratoria sagrada entre los siglos XVII y XVIII: El Epitome de la elocuencia española de Artiga y los modelos de la predicación gerundiana», Annali Online di Ferrara-Lettere, 1, 2008, pp. 124-138.

Tanganelli, Paolo, Le macchine della descrizione. Retorica e predicazione nel Barocco spagnolo, Pavia-Como, Ibis, 2011.

Vega, Lope de, Rimas humanas y otros versos, éd. de A. Carreño, Barcelona, Crítica, 1998.

Vega, Lope de, La hermosura de Angélica, ed. de M. Trambaioli, Madrid-Frankfurt am Main, Iberoamericana-Vervuert, 2005.

Vega, Lope de Arcadia, prosas y versos, ed. de A. Sánchez Jiménez, Madrid, Cátedra, 2012. 